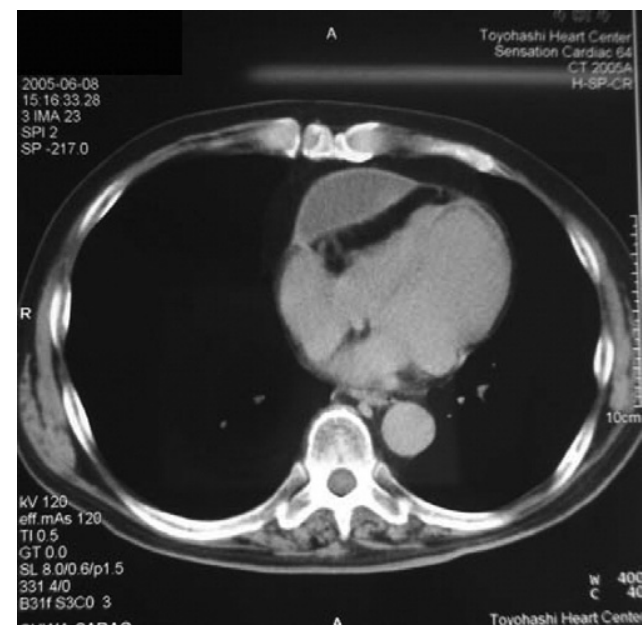

Figure 1. Preoperative computed tomography revealed an abnormal cyst above the heart. The cyst compressed the right atrium and right ventricular outflow.

output. As a result, there would be an increase in V/Q mismatch in zone I pulmonary circulation and increased dyspnea.

Although there is a high incidence of patent foramen ovale in the general population (ie, autopsy studies indicate an incidence of $27 \%$ ), this kind of complication after surgical intervention is occurring more frequently but is not being recognized because of a lack of awareness. ${ }^{5}$ The patient has a history of multiple cerebral
TABLE 1. Cardiac catheterization parameters (supine)

\begin{tabular}{lcc}
\hline & Pressure, mm Hg (mean) & 0ximetry (\%) \\
\hline RA & $(5)$ & 73.9 \\
PA & $13 / 6(9)$ & 75.6 \\
PCW & $(5)$ & \\
LV & $70 /$ edp 8 & 95.4 \\
LA & $(7)$ & 86.2 \\
Ao & $70 / 54(61)$ & 92.8 \\
\hline
\end{tabular}

$R A$, Right atrium; $P A$, pulmonary artery; $P C W$, pulmonary capillary wedge; $L V$, left ventricle; $e d p$, end-diastolic pressure; $L A$, left atrium; $A o$, aorta.

infarctions and the characteristic pattern of occurrence of dyspnea, and these suggested this syndrome. It is important to note the pattern of occurrence of dyspnea for accurate diagnosis.

\section{References}

1. Cheng TO. Platypnea-orthodeoxia syndrome: etiology, differential diagnosis, and management. Catheter Cardiovasc Interv. 1999;47:64-6.

2. Mashman WE, Silverman ME. Platypnea related to constrictive pericarditis. Chest. 1994;105:636-7.

3. Miller DC, Ricks W, Oyer PE, Cipriano PR, Shumway NE. Localized tamponade of the right atrium and right ventricle: Induction of intracardiac right-to-left shunting after the use of a Gott shunt. Arch Surg. 1978;113:764-6

4. Zanchetta M, Rigatelli G, Ho YS. A mystery featuring right-to-left shunting despite normal intracardiac pressure. Chest. 2005;128:9981002.

5. Hussain SF, Mekan SF. Platypnea-orthodeoxia: report of two cases and review of the literature. South Med J. 2004;97:657-62.

\title{
Against the odds: Long-term outcome of drastic-risk cardiac surgery
}

Serban Stoica, AFRCS, Hiremagalur Balaji, MRCS, Adel Helmy, MRCS, Jago Kitcat, BA, Carol Freeman, MSc, Linda Sharples, PhD, and Samer A. M. Nashef, FRCS, Cambridge, UK

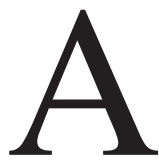

$\mathrm{n}$ average early mortality in low, single-percentage figures is now the norm in most cardiac surgical centers. Nevertheless, the spectrum of risk for individual patients is wide, and there are times when surgeons are called on to perform operations in patients in a precarious situation, for example, with associated comorbidity, an inherent

From the Papworth Hospital, Cambridge, United Kingdom.

Received for publication June 14, 2006; accepted for publication June 28, 2006.

Address for reprints: Samer A. N. Nashef, FRCS, Consultant Cardiothoracic Surgeon, Papworth Hospital, Papworth Everard, Cambridge CB3 8RE, UK

(E-mail: Sam.Nashef@ papworth.nhs.uk).

J Thorac Cardiovasc Surg 2006;132:1226-8

0022-5223/ $\$ 32.00$

Copyright $\odot 2006$ by The American Association for Thoracic Surgery doi:10.1016/j.jtcvs.2006.06.036 risk of complex surgery, or, commonly, both. Risk-assessment models can help identify high-risk patients who require cardiac surgery. Some studies report good results for patients who have a protracted stay in the intensive care unit because of perioperative problems, but the majority of such patients have an acceptable risk to start with. Little is known about the long-term outcomes of drastic-risk cardiac surgery. Are such high-risk, resource-intensive interventions worthwhile?

We sought to determine late survival and quality of life (QOL) in patients undergoing cardiac surgery with a predicted risk of death greater than $50 \%$ at the time of operation. Estimated mortality was calculated using the logistic EuroSCORE because of its good track record for accurately identifying high-risk cases. ${ }^{1}$

\section{Patients and Methods}

Ethical approval for the study was sought and obtained. Of 9971 consecutive patients who underwent cardiac surgery at Papworth Hospital between 1998 and 2004, 142 (1.4\%) had a logistic 


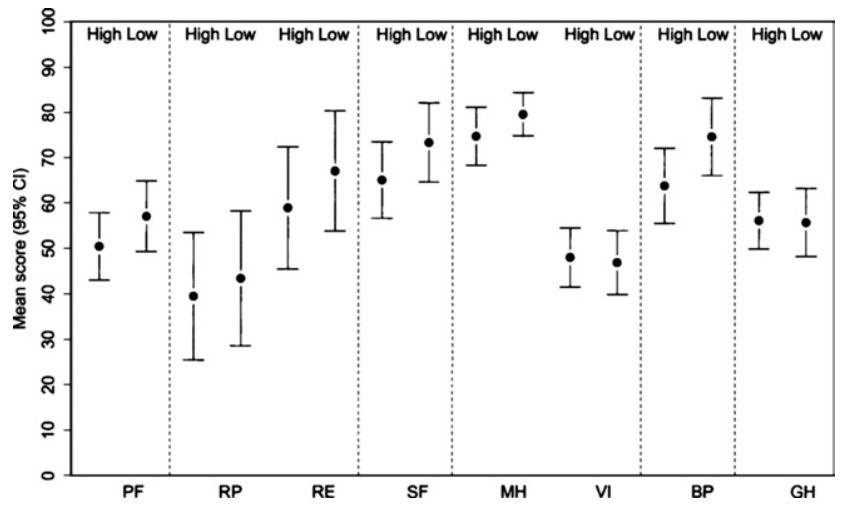

Figure 1. Quality of life SF-36 scores in patients and controls based on high vs low logistic EuroSCORE. Cl, Confidence interval; $P F$, Physical Functioning; $R P$, Role-Physical; $R E$, Role-Emotional; $S F$, Social Functioning; $M H$, Mental Health; VI, Vitality; BP, Bodily Pain; GH, General Health.

EuroSCORE greater than 50. The control group comprised 142 patients matched by age, gender, and time and type of operation. Late survival was ascertained through the National Health Service tracking service to November 2005, estimated using Kaplan-Meier methods and compared using the log-rank test.
Patients alive at follow-up and their controls were posted a Short-Form 36 Health Survey questionnaire to assess QOL in 8 dimensions (Figure 1). Scores range from 0 (worst) to 100 (best). Mean scores were compared using paired Student $t$ tests.

\section{Results}

In the high-risk patients, hospital mortality was 38\% (95\% confidence interval $30 \%-46 \%$; predicted $65 \%, P<.001$ ). For patients discharged from the hospital, survival to 12 months was $86 \%$, compared with $93 \%$ for controls $(P=.07)$.

Sixty-four high-risk patients were alive at a mean follow-up of 4 years (range 1.5-6.8 years), among whom there were 46 paired cases and controls who returned the health questionnaire. Their characteristics are shown in Table 1. High-risk cases stayed longer in the intensive care unit and the hospital. The control group tended toward higher QOL scores in most dimensions, but none of the differences were statistically significant (Figure 1).

\section{Discussion}

This study examines the long-term outcomes of patients who were more likely to die than survive at the time of proposed cardiac surgery. Our main finding is that the QOL attained by survivors of the highest risk operations is comparable to that of other patients of the same age undergoing similar major heart surgery. Although matched by age, gender, and operation type, the two groups are necessarily different in predicted outcome because of the study

TABLE 1. Clinical characteristics

\begin{tabular}{|c|c|c|c|}
\hline Characteristic & Patients ( $n=46$ ) & Controls $(n=46)$ & $P$ \\
\hline Mean (SD) age (y) & $70.6(10.2)$ & $70.2(9.1)$ & .41 \\
\hline Sex F:M & $17: 29$ & $17: 29$ & 1.00 \\
\hline Mean (SD) EuroSCORE logistic & $63.6(11.5)$ & $11.2(9.6)$ & $<.001$ \\
\hline \multicolumn{4}{|l|}{ Priority* } \\
\hline Elective & 9 & 33 & \\
\hline Urgent & 7 & 7 & \\
\hline Emergency & 30 & 6 & $<.001$ \\
\hline \multicolumn{4}{|l|}{ LV functiont } \\
\hline Good & 6 & 16 & \\
\hline Moderate & 11 & 18 & \\
\hline Poor & 29 & 6 & $<.001$ \\
\hline \multicolumn{4}{|l|}{ Operations } \\
\hline CABG & 12 & 12 & \\
\hline Aortic surgery & 13 & 13 & \\
\hline Mitral valve surgery & 3 & 4 (1 with $\mathrm{CABG}$ ) & \\
\hline Aortic valve surgery & 9 (4 with CABG) & 9 (3 with $C A B G)$ & \\
\hline Double-valve surgery & 1 & - & \\
\hline VSD & 7 & 1 & \\
\hline LV aneurysm & 1 & 5 & \\
\hline ASD (+CABG) & - & 1 & \\
\hline Pericardectomy & - & 1 & \\
\hline Median (IOR) ITU stay (d) & $1.4(2.6)$ & $0.9(1.2)$ & .254 \\
\hline Median (IOR) hospital stay (d) & $13.1(13.0)$ & $8.6(4.2)$ & .002 \\
\hline
\end{tabular}

$S D$, Standard deviation; $L V$, left ventricle; $C A B G$, coronary artery bypass graft; $V S D$, ventricular septal defect; $A S D$, atrial septal defect; $I Q R$, interquartile range; ITU, intensive therapy unit. *An urgent operation took place during the same admission, whereas an emergency procedure was performed before the start of the following working day. †LV function was not recorded for 6 controls. 
design. Among other cardiac risk factors and noncardiac comorbidities, the high-risk group had significantly worse left ventricular function and more nonelective operations ( $80 \%$ vs $28 \%)$ than the controls.

The study has two limitations. The first is incomplete followup, with $72 \%$ returning completed questionnaires. Although this is generally an acceptable rate of return, it is possible that nonresponders are different from responders, and this may have biased the results. Second, surgeons and cardiologists may exercise judicious patient selection over and above the information provided by the risk model, so our conclusion may not necessarily apply to all drastic-risk patients.

Although the EuroSCORE itself has been shown to be the most important single predictor of early outcome and resource use after heart surgery, ${ }^{2}$ we showed that it is possible to outperform the logistic EuroSCORE by an important margin. We believe that cardiac surgical centers should measure their own performance in the highest risk subsets before performing cardiac surgery in high-risk patients.

\section{Conclusions}

Our results suggest that despite substantial predicted and actual early mortality, long-term survival and good QOL make cardiac surgery worthwhile in selected high-risk patients. Predicted mortality greater than $50 \%$ alone should not be an absolute contraindication to surgery.

We thank Angela O'Farrell for her support with the Short-Form 36 Health Survey.

\section{References}

1. Michel P, Roques F, Nashef SA. Logistic or additive EuroSCORE for high-risk patients? Eur J Cardiothorac Surg. 2003;23:684-7.

2. Nilsson J, Algotsson L, Hoglund P, Luhrs C, Brandt J. EuroSCORE predicts intensive care unit stay and costs of open heart surgery. Ann Thorac Surg. 2004;78:1528-34.

\title{
Dissection of Kommerell's aneurysm mimicking aortic arch dissection on echocardiography: Multislice computed tomographic diagnosis
}

\author{
Tze-Yu Lee, MD, ${ }^{\text {a }}$ Shu-Hang Ng, MD, ${ }^{a}$ Chi-Di Liang, MD, ${ }^{\mathrm{b}}$ Ming-Jang Hsieh, MD, ${ }^{\mathrm{c}}$ and Sheung-Fat Ko, MD, \\ Kaohsiung, Taiwan
}

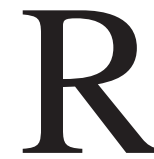

ight-sided aortic arch (RAA) is an uncommon anomaly that occurs in about $0.04 \%$ to $0.1 \%$ of the population. ${ }^{1}$ RAA is generally asymptomatic but can occasionally cause acute aortic symptoms because of dissection or aneurysmal rupture. ${ }^{1}$ Recent studies using imaging modalities, including transthoracic echocardiography (TTE), transesophageal echocardiography (TEE), multislice computed tomography (MSCT), or magnetic resonance imaging, have shown high accuracy in the diagnosis of acute aortic lesions. ${ }^{2-4}$ However, the diagnostic pitfalls of acute aortic diseases on echocardiography in patients with aortic arch anomalies have rarely been described. ${ }^{5}$ We report the MSCT diagnosis of a case of RAA associated with dissection of Kommerell's aneurysm (KA) mimicking aortic arch dissection on echocardiography.

\footnotetext{
From the Departments of Radiology, ${ }^{\mathrm{a}}$ Pediatric Cardiology, ${ }^{\mathrm{b}}$ and Cardiovascular and Thoracic Surgery, ${ }^{c}$ Chang Gung Memorial Hospital- Kaohsiung Medical Center, Chang Gung University, College of Medicine, Kaohsiung, Taiwan.

Received for publication June 23, 2006; revisions received July 14, 2006; accepted for publication Aug 8, 2006.

Address for reprints: Sheung-Fat Ko, MD, Department of Radiology, Chang Gung Memorial Hospital-Kaohsiung Medical Center, 123, Ta-Pei Road, NiaoSung Hsiang, Kaohsiung Hsien, 833, Taiwan (E-mail: sfa.ko@msa.hinet.net or sfatko@adm.cgmh.org.tw).

J Thorac Cardiovasc Surg 2006;132:1228-30

$0022-5223 / \$ 32.00$

Copyright $\odot 2006$ by The American Association for Thoracic Surgery doi:10.1016/j.jtcvs.2006.08.016
}

\section{Clinical Summary}

A 48-year-old man was admitted to the emergency department because of acute sharp chest pain that radiated to his back. He had a 10-year history of hypertension and hyperuricemia. Physical examination was unremarkable, except for increased blood pressure of 168/98 $\mathrm{mm} \mathrm{Hg}$. Electrocardiography revealed slight ST-T elevation in the V1 to V3 leads. Chest radiography showed a widened mediastinum with an RAA and right descending thoracic aorta. Emergency TTE showed an intimal flap in the widened aortic arch (Figure 1) and the descending thoracic aorta indicative of aortic dissection. Possible retrograde dissection to the ascending aorta was also suspected. Subsequent TEE revealed similar findings, but the ascending aorta still could not be definitively evaluated. Emergency surgical intervention was planned under the impression of type A aortic dissection. Before the operation, MSCT (4-detector-row, Volume Zoom; Siemens, Forchheim, Germany) demonstrated an RAA with a right descending aorta, a Kommerell's diverticulum with aneurysmal dilatation, and an aberrant left subclavian artery (ALSA; Figure 2). Dissection of the KA with intimal flaps was clearly demonstrated on axial and multiplanar reconstructed images, corresponding to the misdiagnosed aortic arch dissection on TTE and TEE. The entrance tear was identified at the KA. Extension of the intimal flaps to the ALSA, the right descending aorta, and the abdominal aorta was noted, with sparing of the RAA and ascending aorta, indicating type B aortic dissection. The patient refused surgical treatment of the KA and was conservatively managed with blood pressure and 